\title{
Occupational stress and biomechanical risk in a high fashion clothing company
}

\author{
Laura Forcella ${ }^{\mathrm{a} *}$, Roberta Bonfiglioli ${ }^{\mathrm{b}}$, Piero Cutilli ${ }^{\mathrm{c}}$, Andrea Antonucci a, Angela Di Donato ${ }^{\mathrm{a}}$,Eugenio \\ Siciliano ${ }^{\mathrm{d}}$, Michela Cortini ${ }^{\mathrm{e}}$, Francesco Saverio Violante ${ }^{\mathrm{b}}$, and Paolo Boscolo ${ }^{\mathrm{a}}$ \\ accupational Health Unit, University "G. d'Annunzio" of Chieti-Pescara, Chieti Italy, \\ ${ }^{\mathrm{b}}$ Section of Occupational Medicine, Department of Internal Medicine, Geriatrics and Nephrology, Alma Mater \\ Studiorum-University of Bologna, Bologna Italy, \\ ${ }^{\mathrm{c}}$ EurErg - Ergoteam s.r.l., Rome Italy, \\ d CONTARP (Consulenza Tecnica Regionale Accertamento rischi e Prevenzione), INAIL (Italian Workers' \\ Compensation Authority) Abruzzo, L'Aquila Italy, \\ ${ }^{\mathrm{e}}$ Faculty of Psychology, University "G. d'Annunzio" of Chieti-Pescara, Chieti Italy
}

\begin{abstract}
Psychosocial discomfort may amplify job-related risk factors. The aim of this study is to evaluate job stress in a high fashion clothing company with upper limb biomechanical overload due to repetitive and forceful manual activities. Biomechanical risk was analyzed and in part reduced using the OCRA Check list. A total of 518 workers (433 females and 85 males) were investigated to determine anxiety (by STAI 1 and 2), occupational stress (using the Italian version of the Karasek Job Content Questionnaire) and perception of symptoms. Final biomechanical assessment did not reveal high risk jobs, except for cutting. Although the perception of anxiety and job insecurity was within the normal range, all the workers showed a high level of job strain (correlated with the perception of symptoms) due, probably, to very low decision latitude. It was suggested that job strain may increase the perception of symptoms. Moreover, the result of this study indicates that musculoskeletal overload has to be further analyzed since its low level is not in agreement with the level of discomfort due to the repetitive tasks..
\end{abstract}

Keywords: occupational stress, anxiety, NK activity

\section{Introduction}

Most international and national surveys identify musculoskeletal disorders and stress as the two most frequently reported occupational health problems. Work-related musculoskeletal disorders are characterized by a multi-factorial nature; physical workload (repetitiveness, strength, awkward postures), psychosocial and organizational factors as well as individual factors have been widely recognized as risk factors. In particular, psychosocial discomfort could determine incorrect work methods, capable of amplifying the risk factors themselves.

To evaluate psychosocial discomfort, "Karasek's Job Content Questionnaire"[1,2] proved to be useful in determining occupational stress perceived in rela- tion to work organization in Italian employees and workers in different occupational contexts, for example in a university [3], including a group of teachers [4].

Our group previously carried out an investigation on 300 workers in a high fashion clothing industry, evaluating the work tasks in relation to state of anxiety and reproductive capacity [5]. From this investigation it was ascertained that working activity did not alter the course of pregnancy and was a source of improvement for the family role of the female workers and also for their social life. However, some workers in this factory complained to be suffering from muscoloskeletal disorders. The purpose of this study is to evaluate the psychosocial discomfort mainly related to job repetitiveness.

*Corresponding author. E-mail: laurafox1@virgilio.it 


\section{Materials and Methods}

The study was carried out from December 2008 until April, 2009 in a high fashion clothing company as an anonymous survey using self-administered standardized questionnaires; the state-trait-anxiety inventory (STAI) was used in Scale 1, to measure state-anxiety as a temporary and varying condition, and in Scale 2, to monitor trait-anxiety, as a relatively fixed tendency of the personality [6].

Occupational stress was determined by the Italian version of the Karasek Job Content Questionnaire (JCQ) composed of 49 items: 9 items determined the decision latitude (skill decision + decision authority) (DL), 8 items determined the macro level decision authority, 14 job demand (JD),12 social support (SS) and 6 job insecurity (JI). Job strain (JS) was determined by the ratio JD/DL $[1,2]$.

As reference parameters in table 1 we report the values of occupational stress, observed by our research team in different groups of workers, in part reported in previous studies $[3,4]$; workers such as hospital attendants and those in construction yards showed high job strain (JS) with high levels of job demand (JD), self-employed workers (craftsmen) low JS with high DL; moreover, employees in offices presented low JS with low JD and teachers average JS with high DL.

Perception of subjective symptoms was determined by the Somatization scale of Symptom Check- list SCL-90 [7]; assessing the occurrence of several physical symptoms (e.g. headache, vomit) in the previous week.

The OCRA check list analysis was carried out to evaluate the movements and technical actions using software programs which permit computer management of the filming [8]. In the period between 2005 and 2008, some working positions with presence of biomechanical risk were analyzed; improvements of some working activities were introduced. This article reports the data after reduction of the biomechanical risk, in the period in which job stress was determined.

All qualitative characteristics of workers were summarized as frequency and percentage; all quantitative characteristics, as mean and standard deviation or median and interquartile range, where appropriate. Shapiro-Wilk test was performed to verify normal distribution and resulted to be non-significant; in addition, we checked the skewness and kurtosis, showing values between -1 and +1 for all the variables under investigation. For each variable a two-way ANOVA was applied to assess the overall significance of either each factor (gender and job tasks) and two-way interaction (gender x job tasks). Contrast analysis, a priori specified, was also used to evaluate the difference between different job tasks in male and female employees. All statistical analysis was performed using SPSS ${ }^{\circledR}$ software 11.0 (SPSS Inc, Chicago, IL, USA).

Table 1

Job stress of workers with stable employment and different activities

\begin{tabular}{|c|c|c|c|c|c|c|}
\hline & No. & $\begin{array}{l}\text { Job Demand } \\
\text { (JD) }\end{array}$ & $\begin{array}{l}\text { Decision Latitude } \\
\text { (DL) }\end{array}$ & $\begin{array}{c}\text { Social support } \\
\text { (SS) }\end{array}$ & $\begin{array}{c}\text { Job insecurity } \\
\text { (JI) }\end{array}$ & $\begin{array}{l}\text { Job strain } \\
\text { (JD/DL) }\end{array}$ \\
\hline $\begin{array}{l}\text { Factory } \\
\text { Workers }\end{array}$ & 30 & $\begin{array}{c}30 \\
(31-33)\end{array}$ & $\begin{array}{c}66 \\
(60-70)\end{array}$ & $\begin{array}{c}24 \\
(22.25)\end{array}$ & $\begin{array}{c}10 \\
9-12\end{array}$ & $\begin{array}{c}0.47 \\
0.44-0.53\end{array}$ \\
\hline $\begin{array}{l}\text { Construction } \\
\text { workers }\end{array}$ & 100 & $\begin{array}{c}35 \\
(32-55)\end{array}$ & $\begin{array}{c}59 \\
(56-66)\end{array}$ & $\begin{array}{c}23 \\
(22-24)\end{array}$ & $\begin{array}{c}12 \\
10-16\end{array}$ & $\begin{array}{c}0.56 \\
0.50-0.62\end{array}$ \\
\hline $\begin{array}{l}\text { Hospital } \\
\text { Attendants }\end{array}$ & 296 & $\begin{array}{c}37 \\
(33-41)\end{array}$ & $\begin{array}{c}66 \\
(58-70)\end{array}$ & $\begin{array}{c}23 \\
(20-24)\end{array}$ & $\begin{array}{c}12 \\
11-14\end{array}$ & $\begin{array}{c}0.56 \\
0.5-0.66\end{array}$ \\
\hline $\begin{array}{l}\text { Craftsmen } \\
\text { (self-employed) }\end{array}$ & 15 & $\begin{array}{c}30 \\
(27-32)\end{array}$ & $\begin{array}{c}73 \\
(68-97)\end{array}$ & $\begin{array}{c}24 \\
(23-29)\end{array}$ & $\begin{array}{c}10 \\
9-12\end{array}$ & $\begin{array}{c}0.37 \\
0.33-0.46\end{array}$ \\
\hline $\begin{array}{l}\text { Office } \\
\text { Employees }\end{array}$ & 40 & $\begin{array}{c}25 \\
(23-28)\end{array}$ & $\begin{array}{c}64 \\
(58-75)\end{array}$ & $\begin{array}{c}22 \\
(21-23)\end{array}$ & $\begin{array}{c}11 \\
10-12\end{array}$ & $\begin{array}{c}0.39 \\
0.33-0.47\end{array}$ \\
\hline $\begin{array}{l}\text { School teachers } \\
\text { And professors }\end{array}$ & 373 & $\begin{array}{c}31 \\
(28.34)\end{array}$ & $\begin{array}{c}72 \\
(68-76)\end{array}$ & $\begin{array}{c}22 \\
(20-24)\end{array}$ & $\begin{array}{c}12 \\
10-15\end{array}$ & $\begin{array}{c}0.43 \\
0.37-0.48\end{array}$ \\
\hline
\end{tabular}

Values are median and interquartile range 


\section{Results}

A total of 518 employees participated in the study: 498 were factory workers and 20 office workers, the median age was 40 years (range: $22-62$ years), the mean overall working life was 15.5 years (11.6 of which within this company) (table 2). Age was higher for women than for men; furthermore, the men had a higher percentage of smokers; $90.5 \%$ of the women and $83.7 \%$ of the men had permanent work contracts; the overall working life (but not that of the last job) was higher for women than for men.

The OCRA check list scores, calculated for the main tasks for men and women, for both the right arm and the left arm, are reported in table 3. Sewing and ironing tasks were carried out mainly with the right arm and were classified within the acceptable risk, slightly less than the category with the risk present. Also for the machinists, risk estimation for both limbs was included in the category of acceptable risk. Cutters were classified in the category with the risk present, but only for the right arm .
The table 4 shows that office workers of both genders reported lower anxiety (STAI 1 and STAI 2), more DL, lower JS and perception of symptoms than production workers.

The values of STAI 1 and trait anxiety (STAI 2) of women were significantly higher than those of men ( $p=0.05$ and $p=0.002$, respectively), DL of women was significantly lower $(\mathrm{p}=0.002)$, while SS of women was significantly high $(\mathrm{p}=0.045)$, whilst the perception of JD, JS, JI and subjective symptoms were similar for both genders.

In particular, women working as sewers showed significantly higher perception of SS and of symptoms than men; women working as cutters showed significantly higher trait anxiety (STAI 2) and lower JD than men; on the other hand, the job strain (ratio $\mathrm{JD} / \mathrm{DL}$ ) of both the men and women was similar though men showed higher DL. Finally, women working as ironers showed higher anxiety (STAI 1 and STAI 2) and more SS than men.

Table 2

Age, professional characteristics, education level and smoking habit of the study population

\begin{tabular}{|lcc|}
\hline \multicolumn{1}{|c}{ Variables } & Women & Men \\
\hline & No $=433$ & No.=85 \\
\hline Age (years), median (interquartile range) & $41(36-47)$ & $34(30-38)$ \\
\hline Educational level, $n(\%)$ & & $3(3.6)$ \\
\hline Elementary school education & $37(8.5)$ & $24(28.6)$ \\
\hline Junior high school education & $222(51.3)$ & $53(61.9)$ \\
\hline Senior high school education & $168(38.8)$ & $5(6.0)$ \\
\hline University education & $6(1.4)$ & $71(83.7)$ \\
\hline Stable employment, $n(\%)$ & $392(90.5)$ & $168(120-231)$ \\
\hline $\begin{array}{l}\text { Total period of occupational exposure (months),median (inter- } \\
\text { quartile range) }\end{array}$ & $192(87-276)$ & $120(72-159)$ \\
\hline $\begin{array}{l}\text { Duration of the last job inducing biomechanical } \\
\text { overload (months), median (interquartile range) }\end{array}$ & $120(36-216)$ & $30(15.3)$ \\
\hline Smokers, $n(\%)$ & $52(12.0)$ & \\
\hline
\end{tabular}

Table 3

OCRA check list scores (mean \pm S.D.) for right and left arms of women and divided for type of working activity

\begin{tabular}{|lcc|}
\hline Tasks & Right arm (score) & Left arm (score) \\
\hline Sewers & $9.8 \pm 1,2$ & $5.6 \pm 1.5$ \\
\hline Machinists & $9.9 \pm 0.6$ & $9.7 \pm 0.7$ \\
\hline Ironers & $9.5 \pm 1.5$ & $8.7 \pm 0.5$ \\
\hline Cutters & $13.1 \pm 0.6$ & $3.8 \pm 0.3$ \\
\hline
\end{tabular}

The final score is classified into the following categories: $(<5)$ - risk absent; $(5.1-7.5)$ - risk acceptable; $(11.0-22.5)$ - risk present; $(>22.5)$ high risk 
Table 4

Anxiety (STAI I and II), decision latitude (DL), job demand (JD), social support (SS), job insecurity (JI), job strain (JS: JD/DL) and subjective symptoms of women and men divided by type of job tasks

\begin{tabular}{|c|c|c|c|c|c|c|c|c|c|}
\hline & No. & STAI 1 & STAI 2 & $\begin{array}{l}\text { Decision } \\
\text { Latutude } \\
(\mathrm{DL})\end{array}$ & $\begin{array}{l}\text { Job De- } \\
\text { mand } \\
(\mathrm{JD})\end{array}$ & $\begin{array}{l}\text { Social } \\
\text { Support }\end{array}$ & $\begin{array}{l}\text { Job } \\
\text { insecurity }\end{array}$ & $\begin{array}{l}\text { Job } \\
\text { strain } \\
(\mathrm{JD} / \mathrm{DL})\end{array}$ & $\begin{array}{l}\text { Perception } \\
\text { of } \\
\text { symptoms }\end{array}$ \\
\hline \multicolumn{10}{|l|}{ WOMEN } \\
\hline Sewers & 255 & $39.5 \pm 8.8$ & $40.0 \pm 8.9$ & $51.6 \pm 9.6$ & $32.6 \pm 4.5$ & $22.0 \pm 3.0$ & $12.0 \pm 2.0$ & $0.65 \pm 0.16$ & $9.1 \pm 7.9$ \\
\hline Cutters & 17 & $41.6 \pm 14.0$ & $41.4 \pm 8.5$ & $48.0 \pm 9.2 * \circ$ & $31.2 \pm 3.3$ & $21.6 \pm 4.4$ & $13.8 \pm 1.9^{*}$ & $0.66 \pm 0.11^{\wedge}$ & $6.9 \pm 5.9$ \\
\hline Machinists & 81 & $42.0 \pm 9.0^{*}$ & $41.1 \pm 8.1$ & $54.6 \pm 7.7 * \circ$ & $32.3 \pm 4.2$ & $23.1 \pm 4.4$ & $11.6 \pm 1.9^{*}$ & $0.60 \pm 0.12 * \circ$ & $9.1 \pm 8.2$ \\
\hline Ironers & 22 & $41.0 \pm 7.7$ & $39.0 \pm 6.6$ & $56.1 \pm 4.9^{* \circ}$ & $32.2 \pm 3.7$ & $23.2 \pm 2.4^{*}$ & $12.7 \pm 2.1 \#$ & $0.58 \pm 0.10^{* \circ}$ & $7.5 \pm 7.1$ \\
\hline Some activities & 49 & $40.0 \pm 8.7$ & $41.2 \pm 10.5$ & $52.4 \pm 8.6$ & $32.1 \pm 4.3$ & $22.5 \pm 2.7$ & $12.1 \pm 2.3$ & $0.63 \pm 0.14$ & $9.1 \pm 8.3$ \\
\hline Office workers & 10 & $38.9 \pm 8.9$ & $36.2 \pm 7.3$ & $59.4 \pm 8.0$ & $29.9 \pm 4.3$ & $20.6 \pm 2.5$ & $12.5 \pm 2.0$ & $0.51 \pm 0.10$ & $4.2 \pm 5.2$ \\
\hline Total & 433 & $40.5 \pm 9.5$ & $39.8 \pm 7.0$ & $53.6 \pm 8.0$ & $31.7 \pm 4.0$ & $22.6 \pm 3.2$ & $12.4 \pm 2.0$ & $0.60 \pm 0.12$ & $7.6 \pm 7.1$ \\
\hline \multicolumn{10}{|l|}{ MEN } \\
\hline Sewers & 8 & $39.7 \pm 9.4$ & $35.7 \pm 7.0$ & $51.7 \pm 11.9$ & $31.8 \pm 3.8$ & $19.1 \pm 4.4^{*}$ & $12.2 \pm 1.7$ & $0.62 \pm 0.14$ & $3.8 \pm 3.8^{*}$ \\
\hline Cutters & 20 & $37.1 \pm 11.1$ & $34.9 \pm 7.7^{*}$ & $52.3 \pm 11.0$ & $33.9 \pm 4.5$ & $18.8 \pm 4.9$ & $13.0 \pm 2.0$ & $0.68 \pm 0.22$ & $7.0 \pm 4.8$ \\
\hline Ironers & 35 & $36.7 \pm 9.3^{*}$ & $34.5 \pm 7.8^{*}$ & $53.3 \pm 9.6$ & $33.0 \pm 4.5$ & $21.1 \pm 3.9^{*}$ & $12.5 \pm 2.5$ & $0.64 \pm 0.15$ & $5.8 \pm 5.4$ \\
\hline Some activities & 11 & $36.2 \pm 8.3$ & $37.5 \pm 7.3$ & $55.2 \pm 7.4$ & $32.2 \pm 4.3$ & $21.3 \pm 4.2$ & $12.8 \pm 2.2$ & $0.59 \pm 0.90$ & $5.6 \pm 4.4$ \\
\hline Office workers & 10 & $33.8 \pm 7.6$ & $30.3 \pm 5.5$ & $64.4 \pm 17.5$ & $31.6 \pm 5.5$ & $22.5 \pm 3.8$ & $12.1 \pm 1.7$ & $0.56 \pm 0.31$ & $2.8 \pm 3.2$ \\
\hline Total & 85 & $37.1 \pm 9.1$ & $33.8 \pm 7.0$ & $59.8 \pm 11.4$ & $31.9 \pm 4.5$ & $20.6 \pm 4.2$ & $12.4 \pm 2.0$ & $0.57 \pm 0.18$ & $4.8 \pm 4.3$ \\
\hline
\end{tabular}

The values of DL men and women working in the high fashion clothing company were much lower than those of the blue collar workers in factories and construction yards (reported on table 1), while the levels of JD were similar; because of the very low DL the levels of JS were very high. On the other hand, the values of social support and job insecurity of the workers in the high fashion clothing factory were similar to those of the other group of workers reported on table 1 .

Statistically significant differences among job tasks was observed for DL $(p<0.001), J I(p=0.05)$ and JS $(p=0.020)$, contrast analysis demonstrated that female sewers presented more DL and lower JI than female cutters $(p<0.05)$. On the contrary, sewers had significantly lower DL than machinists $(p<0.05)$, their JS was higher than that of machinists, while their state anxiety (STAI 1) was lower. Moreover, sewers had lower DL $(\mathrm{p}<0.05)$ and SS than ironers, while their JS was higher. Women working as cutters showed lower DL $(p<0.05)$, more elevated JS $(p<0.05)$ and higher JI $(p<0.05)$ than machinists. The female cutters also showed lower DL $(p<0.05)$ and higher JS than ironers. Female machinists presented less JI than ironers. The female office workers showed less anxiety (STAI 1 and STAI 2), JS, SS and perception of symptoms than the blue collar workers (sewers, cutters, machinists, ironers); their DL was higher while there were no difference in the perception of JI.
The women with more than one task (included in the group "some activities") did not show differences among the parameters of perception of anxiety, occupational stress and symptoms.

Table 4 shows that there are no significant differences in the parameters of anxiety, occupational stress or perception of symptoms in the groups of men (in lower numbers than women ) performing different tasks.

\section{Discussion}

The results indicate that anxiety is not a problem in the company. The values of STAI 1 and STAI 2 are in the same range as those reported in recent studies by our research team $[3,4]$. These values also correspond to those collected in an investigation carried out in the same company in 2001 [6]. Moreover, the levels of perception of symptoms reported in this study are similar to those observed in previous investigations on other groups of workers $[3,4]$. It is also known that perception of both anxiety and symptoms is slightly higher in women than in men $[1,2,4]$. This also explains the higher values of STAI 2 observed in women.

The perception of not losing their jobs undoubtedly has a positive role in the workers in this company, not only in the perception of anxiety but also in life 
style and state of health $[3,4]$. However, very low DL values, measured by the Karasek JCQ, were observed in workers of both genders in this company, compared to those determined in other studies on workers with different types of activities (workers, teachers, health service workers, workers in factories and in construction yards) reported on table $1[3,4]$. The low DL values are, therefore, the main element of perception of occupational stress for the blue collar workers of the company.

Table 4 shows that there are no significant differences in the parameters of anxiety, occupational stress or perception of symptoms in the groups of men (in lower numbers than women ) performing different tasks.

The results of biomechanical risk assessment are partially in line with the values of occupational stress. In particular, workers performing cutting activities, presented high OCRA check list scores as well as high stress indexes (high JS, JI and low DL). Biomechanical overload of the right arm seems to be significant also for workers employed in sewing and ironing activities and for machinists; in the latter case both arms are equally exposed.

In conclusion, the results of the analyses on occupational stress show that the perception of job insecurity and of anxiety were within the normal range. However, the analysis of the biomechanical risk in the factory, which this study reports not elevated, has to be continued and improved (also using different diffused and accepted methods) because the results showing a low biomechanical risk are not in agreement with the levels of discomfort due the repetitive tasks.

\section{References}

[1] R.A. Karasek, C. Brisson, N. Kawakami, I. Houtman, P. Bongers and B. Amick. The Job Content Questionnaire (JCQ). An instrument for Internationally Comparative Assessment of Psychosocial Job Characteristics. J Occup Health Psychology 3 (1998), 322-355.

[2] A. Baldasseroni, D. Camerino, P. Cenni, G.C. Cesana, E. Fattorini, M. Ferrario, M. Mariani and R Tartaglia La valutazione dei fattori psicosociali - Il Job Content Questionnaire. Fogli d'Informazione 3 (2001), 20-32.

[3] P. Boscolo, A. Di Donato, L. Di Giampaolo, L. Forcella, M. Reale, V. Dadorante, F. Alparone, S. Pagliaro, M. Kouri, A, Magrini A and E. Fattorini Blood natural killer activity is reduced in men with occupational stress and job insecurity working in a university. Int Arch Occup Environ Health 82 (2009),787-794.

[4] L. Forcella, A. Di Donato, S. Reversi, E. Fattorini and P. Boscolo (2009) Occupational stress, job insecurity and perception of the health status in Italian teachers with stable or temporary employment. J Biol Regul Homeost Agents 23 (2009), 85-93.

[5] S. Kouri, L. Di Giampaolo, E. Toto, T. Cerrone and P. Boscolo P Anxiety, life style and obstetric history of women working in a high-fashion clothing industry. G Ital Med Lav Ergon 23( 2001), 438-441.

[6] C. D. Spielberger CD Manual for the State-Trait Anxiety Inventory STAI Form Y. Mind Garden, Palo Alto, CA (tr. it., Inventario per l'ansia di 'stato' e di 'tratto' forma Y. Manuale, Organizzazioni Speciali, Firenze, 1989.

[7] C. Violani, D. Cariani, A Floresta. Uno strumento per l'autovalutazione del disagio psicologico. In: Mamone P (ed) Atti del I congresso Italiano di Psicologia della Salute. Edizioni Kappa, SCL-90 Roma, 1993.

[8] E. Occhipinti, D. Colombini D. Updating reference values and predictive models of the OCRA method in the risk assessment of work-related musculoskeletal disorders of the upper limbs. Ergonomics 50 (2007), 1727-1739. 